University of Washington Tacoma

UW Tacoma Digital Commons

Social Work \& Criminal Justice Publications

Social Work \& Criminal Justice

$10-1-2018$

\title{
Kept in the Dark: Exploring Children's Preparation for Parental Incarceration and Reentry
}

Diane Young

University of Washington Tacoma, youngd4@uw.edu

Carrie Smith

Follow this and additional works at: https://digitalcommons.tacoma.uw.edu/socialwork_pub

\section{Recommended Citation}

Young, Diane and Smith, Carrie, "Kept in the Dark: Exploring Children's Preparation for Parental Incarceration and Reentry" (2018). Social Work \& Criminal Justice Publications. 511.

https://digitalcommons.tacoma.uw.edu/socialwork_pub/511

This Article is brought to you for free and open access by the Social Work \& Criminal Justice at UW Tacoma Digital Commons. It has been accepted for inclusion in Social Work \& Criminal Justice Publications by an authorized administrator of UW Tacoma Digital Commons. 


\title{
Kept in the Dark: Exploring Children's Preparation for Parental Incarceration and Reentry
}

\author{
Diane S. Young, Ph.D. (Corresponding Author) \\ University of Washington - Tacoma \\ Social Work and Criminal Justice Program \\ 1900 Commerce St. \\ Box 358425 \\ Tacoma, WA 98402 \\ 253.692.4703 \\ youngd4@uw.edu \\ Carrie Jefferson Smith, DSW \\ Syracuse University \\ School of Social Work \\ 284 White Hall \\ Syracuse, NY 13244 \\ 315.443 .5552 \\ cjsmit04@syr.edu
}

We would like to acknowledge the contributions of the young people who shared their experiences with us. Without them this work would not have been possible.

Financial support was provided by the University of Washington - Tacoma Social Work and Criminal Justice Program and the Syracuse University School of Social Work. 
Kept in the Dark: Exploring Children's Preparation for Parental Incarceration and Reentry

\begin{abstract}
Parental incarceration is a challenging and pivotal experience for families. Efforts to prepare children can hinder or promote children's abilities to adapt. Fourteen young adults shared their experiences related to childhood parental incarceration and family reentry through individual interviews. Findings address the research question: How informed and prepared are children for parental incarceration, family reentry, and re-incarceration? Regardless of the parent's stage of criminal justice involvement - arrest, incarceration, reentry, or re-incarceration, participants reported receiving very little information about what was taking place, why, or what they could expect. Small efforts to prepare and inform them were perceived to be helpful as children. Examples of brief interventions that mitigate this experience of being kept in the dark are described.
\end{abstract}

Key Words: Parental Incarceration; Reentry; Children of Incarcerated Parents; Families and Incarceration; Family Communication 
Kept in the Dark: Exploring Children's Preparation for Parental Incarceration and Reentry How do we prepare children for parental incarceration and subsequent family reentry? In the context of the current number of children with incarcerated parents, this is an important question. The U.S. population of minor children with incarcerated parents increased by $80 \%$ between 1991 and mid-2007, the last date that systematic national Bureau of Justice data were collected specifically on prisoners with children (Glaze \& Maruschak, 2010). The consequence is that approximately 1 in every 28 U.S. children (3.6\%) has an incarcerated parent (Western \& Petit, 2010). Glaze \& Maruschak (2010) estimated that there were 1.7 million U.S. children under age 18 experiencing parental incarceration at year-end 2007. In addition, although national data on recidivism rates are silent on the number of parents who are re-incarcerated, estimates are that within three years of release, nearly $70 \%$ of former state prisoners are rearrested for new crimes and 50\% are re-incarcerated (Durose, Cooper, \& Snyder, 2014). Thus, it is reasonable to assume that a large number of America's children are exposed to parents' exiting the family system multiple times due to re-incarceration.

Members of poor urban communities of color disproportionately face incarceration (Wildeman \& Wakefield, 2014). The Pew Charitable Trusts (PEW) (2008) report that although African Americans make up approximately 13\% of the U.S. population, they comprise $40 \%$ of all prisoners. Males in these communities are especially vulnerable to incarceration (Wildeman \& Wakefield, 2014). African American men face the greatest danger of incarceration, having a one-in-three lifetime likelihood of incarceration, compared to one-in-six for Hispanic men and one-in-seventeen for white men (Bonczar, 2003). Once incarcerated, issues of poverty provide little ability for poor prisoners to utilize systems or practices to lessen their confinement through paying for private legal defense, fines or bail (Wheelock \& Uggen, 2006). Mass incarceration of 
people of color "translates into disturbing racial inequities in the population of children affected by incarceration" (Travis, 2005, p. 7). The result for children is that black children are 7.5 times more likely to have an incarcerated parent and Hispanic children are greater than 2.5 times more likely to have an incarcerated parent than white children (Glaze \& Maruschak, 2010). Such inequalities are extreme in many urban centers and can have deleterious effects on almost every facet of family and community life. Notable among these is the resulting gender imbalance in males to females (Travis, 2005) that inhibit both marriage and two parent families. Long-term economic difficulties impact many families experiencing parental incarceration, associated with the initial loss of economic support upon incarceration and the sustained future material hardship and loss of economic mobility (PEW, 2010). Other areas of impact include housing and living arrangements (Casey, Shlafer \& Masten, 2015; Desmond, 2012), school performance (Cho, 2011), and health and mental health concerns (Geller, Garfinkel, Cooper, \& Mincy, 2009; ZahnWaxler, Klimes-Dougan, \& Slattery, 2000).

Few would disagree that incarceration is a stigmatizing experience (Boss, 2010; Morsy \& Rothstein, 2016) that "alters life chances in myriad ways that go to the heart of stratification research" (Wakefield \& Uggen, 2010, p. 388). One possible outcome of such stigma of incarceration is that communication and family efforts to prepare children for parental incarceration and reentry are hindered, essentially leaving children in the dark regarding their parents' whereabouts and wellbeing. Despite the ubiquitous nature of incarceration and the growing population of affected children, very few empirical studies have examined what children know about their parent's incarceration, the preparation they receive for living without their daily presence or for their return to the family at the time of reentry. Descriptive information about the adequacy of this knowledge and preparation can guide intervention efforts 
when working with families and children. This manuscript describes the perspectives and experiences of 14 young adults who faced parental incarceration during childhood. Specifically, we focus on the information about and preparation they received for parental incarceration and subsequent release and return to the family. We address the following broad areas of exploration: How informed and prepared are children for parental incarceration, family reentry, and parental re-incarceration?

\section{Current Understandings of Preparation for Parental Incarceration}

A handful of studies have examined the issue. Sack, Seidler, and Thomas (1976) asked 31 families with 73 children what explanations parents gave their children for the incarceration of a parent. All families in this solely-Caucasian sample had an incarcerated mother or father in correctional facilities in Salem, Oregon. Researchers found that when an explanation was given, it was most often general and vague. In 10 of the families, partial or total deception was used, for example, referring to the prison as an army camp, hospital or school. In another older study in Oregon, Sack and Seidler (1978) assessed 22 children's understanding of the reasons for their father's incarceration. The children were ages 5 to 15 and visited their imprisoned fathers regularly. One third of the children said they did not know or refused to talk about the reasons, and another third told distorted versions of the truth in a way that made the situation seem less severe. Sack and Seidler (1978) found that the six most adjusted children explained the parental incarceration without using denial.

More recent studies also found evidence of vague, distorted, or no explanations given to children regarding their parent's incarceration (Bocknek, Sanderson, \& Britner, 2009; Nesmith \& Ruhland, 2008; Phillips \& O’Brien, 2012; Poehlmann, 2005). Bocknek et al. (2009) found that many of the 35 first through tenth grade children in their sample were not comfortable talking 
about their incarcerated parent's situation, knew few details and wanted to know more. Even among very young children, ages 2.5 through 7.5 years, Poehlmann (2005) found that they knew more than they were told and felt more positively about their caregivers when given honest or developmentally appropriate explanations for their mother's incarceration. Nesmith and Ruhland (2008) found that although $73 \%$ of caregivers thought children knew the incarcerated parent's offense, $43 \%$ of the 8 - to 17 -year-olds in their sample did not know and another $38 \%$ only had vague knowledge that the parent had done something bad or were not sure. Sometimes even with the offer of professional assistance to help a parent provide an accurate explanation, parents resist telling the truth to a child. Phillips and O'Brien (2012) describe one family where the child visited the mother in jail regularly, but was told by the family that his incarcerated mother was in the hospital. The mother resisted staff efforts to help provide a developmentally appropriate explanation.

Information about children's preparation for parental reentry to the family after a period of incarceration is even more scant in the research literature than information about parental incarceration. Yocum and Nath (2011) conducted a study with eight families anticipating a father's release from prison within 12 months. Of the families, only one had a specific release date. This significant lack of basic information likely makes it challenging for families to prepare children for reentry.

Various reasons are offered for why children are given inaccurate and incomplete information about their parent's incarceration. Hairston (2007), in her overview of the research literature focused on children with incarcerated parents, noted the limited research on the reasons given. Explanations offered in parent support groups however, include embarrassment and fear the child will not understand or will lose respect for the incarcerated parent (Hairston, 2007). In 
addition, if the community learns of the incarceration, the family might experience stigma and losses in reputation, employment, or public benefits. Mazza (2002), also drawing on practice experience, explains that children "are lied to for "their own good"' (p. 523). Children are told their parents are in the hospital, took a job elsewhere or are on a job assignment, are at college, serving in the military, or simply moved away (Hairston, 2007; Mazza, 2002).

From a practice perspective, good explanations have been offered for why children benefit from developmentally appropriate and accurate explanations for a parent's incarceration and opportunities to talk about their parent's absence. Children feel abandoned if no explanation is provided (Mazza, 2002). In addition for the children who experience it, witnessing an arrest is frightening. If children are prohibited from talking about it or related fears, they have no way to work through their feelings (Mazza, 2002). Boss (2004) includes incarceration as a situation that can result in "ambiguous loss," experienced by loved ones when someone is physically absent and psychologically present. This type of loss results in confusion "about who is in or out" of the family as well as boundary ambiguity surrounding parenting roles (Boss, 2004, p. 553). Feelings of depression, guilt, and anxiety are common results within the ongoing context of having to live without answers. Ambiguity surrounding a traumatic event is an additional stressor, and family members "fill in" the truth when things are not clear (Boss, 2007). As children get older, it is harder to continue to deceive them about their parent's absence, and deception can affect staying in contact and visitation with a parent (Hairston, 2007). Trust is damaged, with incarcerated parents and with caregivers, if communication within relationships is not open and honest (Poehlmann, 2005). At the time of family reentry, the lack of preparation does not allow for a reconsideration of roles and responsibilities in advance, creating additional stress (Hairston, 2007). 
Overall, empirical information about what children know regarding parental incarceration is missing from most studies on the effects of incarceration. Murray, Farrington, and Sekol (2012) conducted a review and meta-analysis of 40 studies examining effect sizes of parental incarceration on children's mental health, drug use, antisocial behavior, and educational performance. They hoped to include "what children were told about the event" as a moderating variable (Murray et al., 2012, p. 180). So rarely was this reported that they could not. Empirical descriptive information about the level of information and preparation provided to children allows us to assess how well we are doing at assisting children as they adjust to parental incarceration and reentry. That is a contribution of this study.

\section{Methods}

\section{Sampling Procedure}

Fourteen young adults, ages 18 through 28 , consented to share their experiences related to parental incarceration and reentry during the time of adolescence. Many aspects of the participants' adolescent and young adult experiences are reported elsewhere (Smith \& Young, 2017). This manuscript reports findings specifically related to the children's preparation, or lack thereof, for parental incarceration and reentry. The sample and methodology are the same as previously reported (Smith \& Young, 2017). Participants responded to one of several requests that went out with information about the study via emails, listservs, social media and posted fliers. Notices were sent via social work and criminal justice student listservs at two universities and were posted on departmental social media sites (i.e., Facebook, Twitter). The authors also contacted community agencies and asked them to post the flier or share information about the study with appropriate clients. Through these local contacts and additional agency-to-agency sharing of the flier, two community agencies that work with persons involved in criminal justice 
systems, one in the Northeast and one in the Midwest regions of the United States, offered to help with participant recruitment and did so through word of mouth and posting a flier. This broad recruitment strategy resulted in participants from four different states: Pennsylvania, New York, Missouri, and Washington. Although the intent was not to seek out participants from such varied geographic regions, recruitment proved to be a considerable challenge with a smallerthan-expected number of participants coming forward. To increase sample size, we included all prospective participants who met three predetermined study criteria regardless of geographic location.

The predetermined eligibility criteria prospective participants were screened for include: 1) be age 18 through 29 years old, 2) have a parent incarcerated for at least 3 months when the participant was 12 through 17 years old, and 3) the incarcerated parent was significantly involved in the adolescent's life prior to parental incarceration. Participants self-disclosed their age, estimated the length of parental incarceration during their adolescence based on memory, and decided for themselves whether their parent had been "significantly involved." A \$25 gift card was provided to participants as compensation for their time and any transportation-related expenses associated with participation. The study was approved by the Institutional Review Boards of the authors' universities.

\section{Study Design}

After giving informed consent, face-to-face or telephone interviews were conducted with each participant by one of the authors or a graduate social work student who was trained in conducting research interviews. Interviews utilized an interview guide and were semi-structured, consisting of pre-developed, open-ended questions that helped move the participant's narrative through stages of parental incarceration and family reentry. A diagram was created to assist the 
interviewer in moving through the multiple stages of parental criminal justice involvement (see Figure A). Participants were asked to describe in greatest detail the parental incarceration that was most significant to them. This was considered the primary incarceration, although it was not necessarily the parent's first incarceration. Participants were encouraged to share their experiences and perceptions and were given latitude to answer questions briefly or in detail. Questions from the interview guide particularly germane to the findings reported here include items such as, "What were you told about your parent's absence," "Did you feel prepared for your parent's return" and "How were you prepared?" Full interviews ranged from 50-154 minutes, with a mean of 75 minutes. Interviews varied in length in part because some participants were more comfortable with the topic, more generally talkative, or had more stages of parental incarceration and family reentry to move through.

\section{Data Analysis}

Qualitative analysis is especially helpful when the perspectives of participants as insiders are sought on a topic and it is important to understand the contexts that shape those perspectives (Padgett, 2017). The goal of understanding the experiences of parental incarceration and reentry from the perspectives of the children who had these experiences fits well with a qualitative approach. Using an approach informed by phenomenological analysis, our analysis goal is to describe the amount of information and level of preparation children received for parental incarceration, family reentry, and parental re-incarceration. Although disparate in many ways (e.g., geographic location, duration of parental incarceration, age at time of initial parental incarceration), all participants share the common phenomenon of having a parent incarcerated prior to achieving adulthood. We considered their lived experiences, looking for salient themes across participants' accounts (Padgett, 2017). 
All interviews were conducted, taped and transcribed prior to analysis. Once a transcript was received from the transcription service, one of the authors or graduate students listened to the interview audiotape while reading along with the transcript as a way of double checking the accuracy of the transcription, noting and correcting any detected errors. Analysis was then conducted on the proofread transcripts. First using an open coding process, all relevant participant comments, whether a phrase or whole story, to each question in the interview guide were placed in Word documents. This resulted in a Word file for each interview guide question and its corresponding participant responses. Throughout this process, the authors consulted with each other if there was uncertainty about where to place a comment. Because the transcripts in their entirety were reviewed, not just the section of the interview that directly asked each question, the result was a more complete array of responses for the next level of analysis. During the next stage of analysis, both authors read through the created Word files in order to identify broad salient themes emerging from participants' experiences. Then, the first author conducted a more detailed, nuanced analysis of the salient themes relevant to the overarching research questions addressed in this manuscript. Attention was paid to similarities and differences across participants' experiences and to the expressed dimensions of the broader themes. Written summaries were prepared that included the identified themes and their dimensions. These were reviewed by the second author to determine whether the conclusions drawn "rang true" to the narratives. Any areas of disagreement were discussed and reconciled by re-reviewing the original transcripts. To strengthen the trustworthiness of the study, strategies to enhance the credibility and confirmability of the data analysis were employed. These included engaging in a systematic and planned analysis process, the concerted effort to pay attention to the wide variation of participants' experiences expressed in the narratives, a careful recording of 
process decisions throughout, and continuous checking in and double-checking of each other's analysis process and conclusions.

Children's lack of preparation for parental incarceration and reentry emerged as a predominant and recurring theme during the qualitative analysis of the full scope of questions in the interview guide. Because there is very little empirical exploration of this phenomenon reported in the research literature, data about children's level of preparation for parental incarceration and reentry helps address this gap.

\section{Sample Description}

At the time of the interviews, participants ranged in age from 18 to 28 -years-old. Four of the fourteen participants identified as male. Six were African American, six Caucasian, and two Hispanic. The majority of participants had had a father incarcerated, nine biological and two stepfathers. Three participants had had their biological mothers incarcerated. Only two of the incarcerated parents did not live with their children prior to their incarceration. Participants reported their parents were incarcerated for crimes involving drugs, fraud, arson, child molestation, and murder. They were incarcerated from 6 months to life, with 10 of the parents serving more than 2 years in prison. Six of the parents were incarcerated once; 3 were incarcerated twice; 5 were incarcerated 3 or more times. Two parents will not be released during their lifetimes based on the length of their sentences.

\section{Findings}

This manuscript focuses on the perspectives and experiences of the participants related to the information about and preparation they received for parental incarceration and subsequent family reentry. We address here the following broad research questions: How informed and 
prepared are children for parental incarceration, including multiple incarcerations? How informed and prepared are children for family reentry after a parental incarceration?

\section{Preparation for Parental Incarceration}

The ages of the participants at the time of the parent's primary incarceration varied greatly. Of the 14, seven (half) were in the adolescent age range of 12 through 17 . The others ranged in age from 2 through 11 . Three of the 14 witnessed the arrest or part of the arrest. They were ages 6,8 , and 10 . Because of this, they had immediate knowledge that the parent was in trouble and something serious was happening. In two of these instances, the remaining custodial parent or the parent who was being arrested explained in brief detail that the arrested parent was going to jail and it was not known how long he would be away. In the third case involving the 8year-old, Children's Protective Services (CPS) had interviewed her at school that day, but no parent or adult explained what was taking place. When interviewed for the study, this participant said she did not understand why everyone tried to keep information from her because a sister told her everything anyway. Even though no one ever said to her that her father was charged with child molestation of a sibling, she said she knew to lie to CPS and was not surprised by the arrest or accusations against her father.

Given the young ages of half of the children, it is understandable that complete information was not provided at the time. One mother told her six-year-old daughter that "daddy did a bad thing" and "he was going away for a really long time" and probably not ever coming home. She did not tell her that her father had been arrested for murder. Another whose father was incarcerated when he was only two, began asking at about the age of six, "where's daddy, where's daddy?" When interviewed as a young man, he said his mother kept him and his siblings "clueless" and would not address his questions. In both of these cases, the participants 
ferreted out the information for themselves when a bit older. The latter, through contact with his incarcerated father, was able to piece together some information regarding his father's crime and incarceration. The former as a teenager, went into her grandparents' files at their home and read everything she could find on her father's crime and sentence. She explained how it happened:

I was watching my grandfather's house, like watering the flowers. And my mom had dropped me off over there one day, and I knew that my grandfather kept a file in his filing cabinet on my dad and everything and so being the curious teenager that I was I went in and read everything. So I kind of found out on my own.

She then went to her mother with additional questions. That was the first she learned that her father had been sent to prison for murder. Even though a developmentally appropriate explanation had been provided to her as a young child, as she got older that explanation was no longer satisfactory.

The uncertainties associated with criminal justice procedures and systems contribute to the lack of information and preparation for parental arrest and incarceration. For example, only a few of the children were told at the same time they learned of their parent's incarceration how long the parent would be away. This is understandably not something that arresting officers or the defendant would know during the beginning stages of criminal justice system involvement. Even when known however, families and children of incarcerated parents are not always informed or the information is not delivered in such a way that children are able to understand. One participant who was 11-years-old at the time of her mother's incarceration was present at the sentencing hearing and heard the judge issue the sentence. Nonetheless, when interviewed for the study she said she did not really understand what was happening at the time; she remembers trying to process the information in the moment without much success. 
I'd say about a month before she [her mother] actually got sentenced, we went to visit her lawyer and I didn't really know what we were doing. I really didn't have a clue as far as that was concerned....So, fast forwarding a bit within that month's time, all I remember is sitting in a courtroom and them discussing her sentence...And that was it. It was pretty much gavel comes down, judgment's made and from that point on, it was just within that moment just processing what went on because I wasn't very clear about it.

Thus, even though she was present at sentencing, had been in the lobby when her mother met with an attorney earlier, and had heard mention of prescription drug abuse in relation to her mother's case, she was not at all prepared for the outcome of her mother's incarceration. Another who was 12-years-old at the time of parental incarceration said her father had a conversation with her and her brother, telling them he was going to prison. She experienced it as "a blur" and conveyed that it seemed to happen very quickly. She did not know why he was going to prison; that was not explained. Similar to the two participants discussed previously who took it upon themselves to learn more at a later time, she also learned more about the crime when she was older and her father was released. She wished she had been told more at the time, explaining:

I almost just wish that my parents would have been more up front like if something was happening. Because even if I wouldn't have been able to, like, understand then, I feel like a lot of the stuff that I'm dealing with now is the result of like me trying to...repress a lot of the things....Like, I had to find out things the hard way...nobody would actually tell me....I wish they would've just told me and worked through it with me rather than like have to do it kind of like on my own. 
In half (seven) of the participants' cases, the non-incarcerated parent or an extended family member was the one who conveyed the news about parental incarceration. Five participants were eventually told by their mothers, one by a live-in grandmother, and one by her step-brother's family. Sometimes this was done fairly immediately and at other times, news of the incarceration was much delayed. For example, one 12-year-old was told by her father that he would be back later that day. That evening after he did not return, her mother told her that her father was in jail and that they would have to figure out how to live without Dad because he would not be back for perhaps 10 years. The participant described this last experience with her fathers as follows:

I didn't know that he was going to prison. I remember the last time I had seen my dad, I had come home and we had French fries for lunch. He told me he was going to his sister's house who lived about three or four blocks away. He told me he would be back before my mom got home from work. And later on that night, I guess my mom talked to him and she told me he went to jail.

In contrast, a 16-year-old after trying to call her (non-live-in) father for about three months, asked her mother about him. She was then informed he had gone to jail. The participant did not think they were trying to keep a secret but rather just wanted to make things as easy as possible for her. She explained,

I didn't even know he was actually in jail until about, maybe three months after he was. And he was ignoring my phone calls, I thought he was, until I asked my mom and she told me that he went back to jail....I think she found out...maybe a few weeks before and she wanted to figure out how to tell me and make it easier for me. She didn't really try to keep it a secret. 
In retrospect, his incarceration was not a surprise. She knew her father had started using drugs again, and that is what he had been incarcerated for previously. This delay in her finding out likely would have been impossible if the father had lived in the same home. In a similar circumstance where the father was often away, a participant who was nine at the time noticed that her father had not been there for a while and her mother was stressed. Eventually her mother sat her down and told her that her father had been arrested. Mom did not know when he would be back, but did assure her daughter that she would be able to see him. Once the initial conversation took place, several other conversations followed. These conversations happened over time at a pace that the child could manage. She would get answers to her questions, become upset and not want to talk about it for a long time, and then initiate another conversation with her mother when ready.

Perhaps understandably, in cases where the parents were estranged, information regarding a parent's incarceration was even more limited or non-existent. In one such example, a participant stated he just knew his father was gone for a long time, but that he was not told anything. His explanation for this was that his parents were not close. Sometimes the information that a parent has gone to jail comes from outside both the family and criminal justice agency personnel. One participant who was 16 at the time of her mother's arrest for drug possession stated that she "got a knock on the door saying that [her mother] had been incarcerated and that she had to do some time." This information came from someone in the neighborhood, probably a fellow drug user of her mother's. The participant's mother called two days later and told her children she received a sentence of 120 days.

In summary, in most cases information about the parent's incarceration was not immediate and was incomplete. In addition from the participants' perspectives, very little, if 
any, consideration was given to preparing them for the ensuing parental absence. Participants, as adolescents, had many unanswered questions, such as how the criminal justice system works, how to go about getting an attorney for a parent, and who would take care of them.

\section{Preparation for Family Reentry}

Participants were asked whether they felt prepared for their incarcerated parent's release and return to the family. For five of the 14 participants, their parent remained incarcerated or was released after they were grown and living on their own and thus they did not experience parental reentry to their homes or in their day-to-day lives. Of the remaining nine participants, five experienced their parent's release when they were adolescents, ages 12 through 17; two had parents released when they were young adults, 19 and 21, but not yet living on their own. The remaining two participants' parents were released from the primary incarceration when the participants were ages 10 and 11. Only two of the nine participants stated they felt prepared. One 13-year-old explained that she believed her father's incarceration was a one-time thing, never to be faced again, so she felt ready to have Dad home. As it turned out, her father was incarcerated two more times. The other, a 17-year-old, credited her preparation to a letter received from her incarcerated mother.

The remaining seven participants who experienced family reentry of an incarcerated parent expressed little to no preparation or even time to adjust to the news and the homecoming. Almost no advance notice was given, with participants typically told within a few days of release. Although there is the common experience of surprise, each one's circumstances were a bit different. In one case, there was little notice given of the release, but as it turned out, the incarcerated parent could not get cleared by probation to leave the state until 6 months post- 
release. This too was unexpected. Even so, now a college student, she explained her sense of readiness for her father's homecoming as follows:

Well, my emotions were very mixed. I wasn't really prepared. I think he had been away for so long, and I had grown up. I'd changed so much within those three years, from 17 to 21 . It was my entire undergrad career. I'd changed so much - I had very mixed feelings about it. Okay, well now that's he's back, what am I going to do?...I was very afraid, actually, of what he was going to come in and try to change now that we had instituted something, our own type of values just in that home....I went and I saw him, and I was so happy to see him. I hugged him, but it was really awkward and emotional. I was definitely unprepared.

In another case, secrecy surrounded the time of release, and only the month of release was given the family by the federal prison. The participant described her experience this way:

One of the last conversations she had with my father while she was away was when she was coming home, when she was expected to be home because one of the main things I remember is secrecy....They had a roundabout date of when she would come home. We knew it would be in the month of March. We didn't quite know when it would be. So, basically when she was coming home, she called when they were releasing her and she was like 'I'm taking a plane. I'll be home around this time.' So, I wasn't prepared because even though I knew she was coming home in the month of March, I think I was least prepared emotionally.

For another daughter, her father was released unexpectedly on the day of sentencing. Ten-years-old at the time, this participant and her little sister were told they were going home rather than back to their older sister's who had been caring for them and where all their clothes 
were kept. They were simply told, "Your dad's back, so you get to go hang out now [with him]." A 19-year-old participant, seriously mistreated as a child by his mother and living with his grandmother, was told the day before that his mother was getting released and moving back in with them. A 17-year-old was asked by her aunt, her incarcerated father's sister, via Facebook to call. When she did she was told that her father was being released. She described the experience as follows:

...we're friends on Facebook and she told me to call her and even with that, I was hesitant because I knew it had to be something about my dad because I didn't speak to her or that side of the family unless it had something to do with my dad. So, I called her and she told me that he was going to be coming home and living with her for a little while and she asked me if I wanted to come like stay with her for a little while and spend time with him and I said no....And she got mad at me...that whole side of the family got mad at me... and they yelled at me and they were like 'he's your father' and I was like 'no, he's not - he might be my dad but he's not my father.' That's what I said to her and that's still how I feel because he's just absent. He's an absent dad.

Somewhat similar to this, an incarcerated father called his 15 -year-old son, told him he was getting out, and asked him if he would come and visit.

So he was like, ‘Are you going to come see me?' And I didn't. I mean, I came to see him, but I didn't go spend the night at his house and stuff like that. My older brother did, but...I already wrote him off. At that point it didn't matter if he was dead or alive, in my life. He wasn't there. 
Finally, one participant's mother told him and his brothers “"your father's going to be coming home in a couple days'... and ...we [are] going to shoot him a little party." They went shopping for clothes and food for his father. This was his explanation of the preparation he received.

In summary, for the majority of participants who experienced parental reentry, notice and preparation for release and reentry were about as minimal as notice and preparation for the parent's incarceration. Upon a parent's return home, participants particularly had questions about how to relate to their parent. One 12-year-old participant commented about her released mother: "I didn’t really know how to address her. I knew she was my mother, I knew she was still a good person, all those things, but I was just like 'I don't know what to do with you."” This was after only a relatively short sentence, 6 months in prison.

\section{Preparation for Parental Re-incarceration}

Five participants experienced the re-incarceration of a parent while still minors. Two were surprised and unprepared for a parent's return to prison or jail, and three were not surprised based on the parent's behavior, but still received no preparation. One was surprised because she did not expect her father to break her trust again. She thought they would follow through on the future plans he assured her about. She explained,

I didn't expect him to go back a second time, so like when he said like 'Oh, we're gonna get this, we're gonna get this, we're gonna get this,' like I believed him. Because like I didn't think that he would want to do something, especially from going away the first time, to like break my trust again.

The other participant was surprised because his father did not seem to be doing anything to warrant criminal justice involvement. At the time of the interview he still did not understand what had happened and expressed experiencing the re-incarceration as sudden. 
I wasn't expecting it. I don't know why, it didn't seem like he was doing anything.... Then all of a sudden, he just went back to jail. It didn't make any sense to me. It still doesn't make sense to me, now. He just went back. Out of the blue. That's what was hard. It was like, why is he going back to jail?

Those that were not surprised saw changes in the parent's behavior such as breaking the law and using drugs. For these participants, the following was a common realization:

It was kind of the same thing. I knew he was breaking the law. I guess I wasn't counting down the days, but I wasn't surprised. I didn't know when it would happen, but I thought it probably would happen.

Another had seen her father go in and out of jail so many times that she accepted this pattern as part of the family routine even though she was not aware that her father was using drugs. These children believed it to be just a matter of time before the parent returned to jail or prison. Even when re-incarceration was expected based on a parent's illegal behavior, the event created challenges for some participants. For example, one participant deeply resented having to break the news to her younger sister, who was close to their father. The lack of preparation given her meant that she was expected to make living arrangements for her younger sister.

\section{Discussion}

Regardless of the parent's stage of criminal justice involvement - arrest, incarceration, release and reentry, or re-incarceration, the young people in our sample consistently remembered receiving very little information about what was taking place, why, or what they could expect. They also received little to no assistance or supports managing the attendant emotions or preparing for their parent's incarceration, reentry to the family, or re-incarceration. Although it might be understandable that there is little forewarning prior to arrest and immediate 
incarceration, in situations where parents are serving a given sentence, we ought to be able to do a better job preparing children for parental reentry.

Although we can make some assumptions, it is not clear why primary caretakers and parents do not communicate more directly when a parent is incarcerated. Stigma may be a contributing factor. Regardless, maintaining secrecy poses risks to the wellbeing of children who must then struggle with managing the stigma (Luther, 2016) and the ramifications of keeping family secrets. The result may be difficulties on multiple fronts. First are the accompanying troublesome emotions children experience, including anxiety, fear, depression, or self-blame that often come with sensing that something is wrong, that they have been "marked" in some way, and no one is talking about it. Compounding this may be the sense of unacknowledged loss that these youngsters are experiencing. Boss (2007) has identified the concept of ambiguous loss to identify situations where there is uncertainty about a loss, often in the context of other stressors. The uninterrogated truth that children create in the silence of unanswered questions, only adds to the trauma and loss that these children experience.

Furthermore, children may feel that they will be judged if they reveal the family's hidden stigma (Pachankis, 2007).

Custodial caregivers may well be avoiding talking to youngsters about upsetting information as an act of kindness in an effort to protect them, however, this approach is likely more damaging in the long-run. Children are often more aware of the truth about the parent's incarceration than the caregiver may realize (Hairston, 2007). Several of our participants ferreted out answers to questions about their incarcerated parents that remained unanswered in the silence from their parental caretakers. Withholding information and maintaining secrecy contribute to a sense of uncertainty and stigmatization that erode developmental foundations of 
security for children and deny them the opportunity to develop more appropriate and healthy coping skills (Link and Phelan, 2001; Pachankis, 2007).

\section{Practice and Policy Implications}

Strategies and resources to assist families in preparing children for parental incarceration and family reentry are available. For example, the National Resource Center on Children and Families of the Incarcerated (https://nrccfi.camden.rutgers.edu/) provides a directory of national, state and local programs, fact sheet on incarceration and families, and access to The Children of Incarcerated Parents Library with resources in English and Spanish to assist families in responding to and communicating about the realities of parental incarceration. Also Rothrauff's (2008) pamphlet available via the internet and titled "When a Child's Parent is Incarcerated" is a helpful resource for understanding some of the concerns that kinship caregivers have and for advice about how to communicate with children in a sensitive and age appropriate way.

It is not uncommon for children of an incarcerated parent to wonder about their parent, asking questions such as "Where are you?," "Why are you there?," "When are you coming home?," and "Are you ok?" (Adalist-Estrin, n.d., p. 1). Children also wonder, "Do you blame me?," and "Do you love me?" (Adalist-Estrin, n.d., p. 1). They will not necessarily be forthcoming with these questions however, especially if they do not know how to express their concerns or if they perceive that the topic is off limits. One suggestion for opening up a conversation with a child comes from the authors of a study that examined youths' understandings of jail and offenders (Folk, Dallaire, \& Zeman, 2014). An "Understanding of Incarceration" measure was developed that included questions such as "Why do people go to jail?," "What kinds of people go to jail?," and "Are people safe while they are in jail?" (Folk et

al., 2014, p. 127-128). Questions such as these and others included in their measure can be used 
by custodial parents and caregivers to gently explore with a child his or her current understandings and concerns about parental incarceration and to share accurate age-appropriate information.

Over time, progressive explanations responsive to the developmental maturation of young people are most helpful. The example of the participant in our sample who was provided an age appropriate explanation of her father's incarceration when very young, but later as a teenager was not satisfied with that answer exemplifies this. A resource for teenagers is available through Project WHAT! (2008). Although focused locally on helping those in the San Francisco Bay area, Project WHAT! provides an 80-page downloadable-for-free resource guide written by teenagers and young adults who have had an incarcerated parent. The teen-friendly guide addresses numerous questions relevant to basic needs, prisons and jails, legal processes, and accessing services.

In our sample, small efforts to inform and prepare children were perceived as helpful. These included a letter from an incarcerated mother prior to her release and conversations between a non-incarcerated parent and child that took place over time and addressed the child's questions. Based on the difficulties experienced by our participants' families in sharing information and preparing children, parents and caregivers need assistance to know how and what information to share. In poor urban communities where the number of incarcerated citizens is high, community centers might provide a help desk or a routinized drop-in opportunity for families and youth to seek information in a non-threatening way. Such an auxiliary service might also be housed in local school facilities, places of worship, or community health centers, as a response to mental health needs. Mentoring opportunities that connect children of incarcerated parents to successful adults who have experienced parental incarceration, could 
model tangible hope for the future. The mentors could also provide a touchstone for communication between the child, caregiver, and mentor.

A collaborative and systemic policy response to the multifaceted problems that result from mass incarceration and powerfully impact so many families and children are required to facilitate meaningful change and resolution. Community wide discussion of the impacts of mass incarceration is a powerful mechanism to acknowledging the impacts on poor and minority communities. Better understanding of the issues and a full engaging of communities should lead to building bridges to sustainable solutions. In the end, the long-term goal is to greatly reduce the need for and use of incarceration, an "upstream" intervention and response, rather than solely focusing on assisting those families and children impacted by it, a "downstream" response.

\section{Limitations and Future Research}

As previously reported (Smith \& Young, 2017), one of the most challenging methodological aspects of doing this study was recruitment. We recruited widely using various techniques over an extended period, and 14 individuals chose to participate. Some of the participants spoke about how difficult it was to talk about the subject, indirectly offering a possible explanation for the challenge in recruiting. Despite the small number of participants, there is growing evidence that sample sizes as small as 6 individuals in qualitative studies are sufficient for adequately surfacing the majority of themes found in larger samples (Francis et al., 2010; Guest, Bunce, \& Johnson, 2006; Hennink, Kaiser, \& Marconi, 2016), providing confidence that a robust array of relevant themes are present among our sample. An additional methodological challenge was that for the interview questions that are the foci of these analyses, participants had to rely on their ability to recall details and experiences that happened some years ago, when they were children. The memories and perspectives are those they hold in the present 
as they reflect on earlier times; if they had been interviewed as adolescents, their perspectives and recall of details may have been different. In addition, our participants were not available for multiple or follow-up interviews, typical of a phenomenological approach (Padgett, 2017). Qualitative research studies that are able to employ strategies such as conducting multiple interviews with participants or member checking would increase depth and confidence in the findings' dependability.

Future research might address these limitations by finding additional access points to children of different developmental stages who are experiencing parental incarceration. Further research is also needed with parents, both the incarcerated and the ones left behind, and kinship and other caregivers, to better understand their motives and strategies for preparing or not preparing children for parental incarceration and family reentry. It might be especially useful to know what resources might help them better communicate about this challenging issue with children.

\section{Conclusion}

Our findings on the preparation of children for parental incarceration and family reentry add empirical support to findings from previous research studies and to expressed practice concerns that children are essentially kept in the dark regarding these and other questions about their loved ones. As a consequence, children experience negative emotions and outcomes that might have been at least partially mitigated. Children with incarcerated parents need ageappropriate and accurate information and resources that inform them about what to expect and that support them in ways that reduce the trauma and hardship associated with parental incarceration. In addition, minority and poor urban communities that are disproportionately 
impacted by incarceration need community wide engagement and socially just policies and interventions to systemically address the negative impacts on children and families. 


\section{References}

Adalist-Estrin, A. (n.d.). Conversations: Questions children ask (CIPL 103). Rutgers-Camden: Children of Incarcerated Parents Library. Retrieved from https://nrccfi.camden.rutgers.edu/files/cipl103-conversations-questionschildrenask.pdf

Bocknek, E. L., Sanderson, J., \& Britner, P. A. (2009). Ambiguous loss and posttraumatic stress in school-age children of prisoners. Journal of Child and Family Studies, 18, 323-333. doi:10.1007/s10826-008-9233-y

Bonczar, T. P. (2003). The prevalence of imprisonment in the U.S. population, 1974-2001. Washington, DC: U.S. Department of Justice. Retrieved from http://www.cbsnews.com/htdocs/pdf/prisontime.pdf

Boss, P. (2004). Ambiguous loss research, theory and practice: Reflections after 9/11. Journal of Marriage and Family, 66(3), 551-566.

Boss, P. (2007). Ambiguous loss theory: Challenges for scholars and practitioners. Family Relations, 56(2), 105-111.

Boss, P. (2010). The trauma and complicated grief of ambiguous loss. Pastoral Psychology, 59(2), 137-145. doi:10.1007/s11089-009-0264-0

Casey, E. C., Shlafer, R. J., \& Masten, A. S. (2015). Parental incarceration as a risk factor for children in homeless families. Family Relations, 64(4), 490-504. doi:10.1111/fare.12155

Cho, R. (2011). Understanding the mechanism behind maternal imprisonment and adolescent school dropout. Family Relations, 60(3), 272-289. doi:10.1111/j.1741-3729.2011.00649.x

Desmond, M. (2012). Eviction and the reproduction of urban poverty. American Journal of Sociology, 118(1), 88-133. doi:https://doi.org/10.1086/666082 
Durose, M. R., Cooper, A. D., \& Snyder, H. N. (2014, April). Recidivism of prisoners released in 30 states in 2005: Patterns from 2005 to 2010 (NCJ 244205). Washington, DC: U.S. Department of Justice.

Folk, J. B., Dallaire, D. H., \& Zeman, J. L. (2014). High-risk early adolescents’ perceptions of jail and offender experiences. Applied Psychology in Criminal Justice, 10(2), 106-128.

Francis, J. J., Johnston, M., Robertson, C., Glidewell, L., Entwistle, V., Eccles, M. P., \& Grimshaw, J. M. (2010). What is an adequate sample size? Operationalising data saturation for theory-based interview studies. Psychology and Health, 25(10), 12291245.

Geller, A., Garfinkel, I., Cooper, C. E., \& Mincy, R. B. (2009). Parental incarceration and child well-being: Implications for urban families. Social Science Quarterly, 90(5), 1186-1202. doi:10.1111/j.1540-6237.2009.00653.x

Glaze, L., \& Maruschak, L. (2010, March). Parents in prison and their minor children (NCJ 222984). Washington, DC: Bureau of Justice Statistics.

Guest, G., Bunce, A., \& Johnson, L. (2006). How many interviews are enough?: An experiment with data saturation and variability. Field Methods, 18(1), 59-82.

Hairston, C.F. (2007, October). Focus on children with incarcerated parents: An overview of the research literature. Baltimore, MD: Annie E. Casey Foundation.

Hennink, M. M., Kaiser, B. N., \& Marconi, V. C. (2016). Code saturation versus meaning saturation: How many interviews are enough? Qualitative Health Research, 27(4), 591608.

Link, B. G., \& Phelan, J. C. (2001). Conceptualizing stigma. Annual Review of Sociology, $27(1), 363-385$. 
Luther, K. (2016). Stigma management among children of incarcerated parents. Deviant Behavior, 37(11), 1264-1275. doi:10.1080/01639625.2016.1170551

Mazza, C. (2002). And then the world fell apart: The children of incarcerated fathers. Families in Society: The Journal of Contemporary Human Services, 83(5/6), 521-529.

Morsy, L., \& Rothstein, R. (2016). Mass incarceration and children's outcomes: Criminal justice policy is education policy. Washington, DC: Economic Policy Institute. Retrieved from www.epi.org

Murray, J., Farrington, D. P., \& Sekol, I. (2012). Children's antisocial behavior, mental health, drug use, and educational performance after parental incarceration: A systematic review and meta-analysis. Psychological Bulletin, 138(2), 175-210. doi:10.1037/a0026407

Nesmith, A., \& Ruhland, E. (2008). Children of incarcerated parents: Challenges and resiliency, in their own words. Children and Youth Services Review, 30(10), 1119-1130. doi:10.1016/j.childyouth.2008.02.006

Pachankis, J. E. (2007). The psychological implications of concealing a stigma: A cognitiveaffective-behavioral model. Psychological Bulletin, 133(2), 328-345.

Padgett, D. K. (2017). Qualitative methods in social work research ( ${ }^{\text {rd }}$ Edition). Thousand Oaks, CA: Sage.

Pew Charitable Trusts. (2008). One in 100: Behind bars in America 2008. Washington, DC: The Pew Charitable Trusts.

Pew Charitable Trusts. (2010). Collateral cost: Incarceration's effect on economic mobility. Washington, DC: Pew Charitable Trusts.

Phillips, S. D., \& O'Brien, P. (2012). Learning from the ground up: Responding to children affected by parental incarceration. Social Work in Public Health, 27(1-2), 29-44. 
Poehlmann, J. (2005). Representations of attachment relationships in children of incarcerated mothers. Child Development, 76(3), 679-696.

Project WHAT! (2008, May). Resource guide for teens with a parent in prison or jail. Berkeley, CA: ProjectWHAT! Retrieved from www.communityworkswest.org/program/project-what/

Rothrauff, T. (2008, April). When a child's parent is incarcerated. Columbia, MO: University of Missouri Extension. Retrieved from http://extension.missouri.edu/publications/DisplayPub.aspx?P=GH6202

Sack, W. H., \& Seidler, J. (1978). Should children visit their parents in prison? Law and Human Behavior, 2(3), 261-266.

Sack, W. H., Seidler, J., \& Thomas, S. (1976). The children of imprisoned parents: A psychosocial exploration. American Journal of Orthopsychiatry, 46(4), 618-628.

Smith, C. J., \& Young, D. S. (2017). A retrospective look at the experience of parental incarceration and family reentry during adolescence. Social Work in Public Health, $32(8), 475-488$.

Travis, J. (2005). But, they all come back: Facing the challenges of prisoner reentry. Washington, DC: The Urban Institute Press.

Wakefield, S., \& Uggen, C. (2010). Incarceration and stratification. Annual Review of Sociology, 36(1), 387-406. doi:10.1146/annurev.soc.012809.102551

Western, B., \& Petit, B. (2010). Collateral cost: Incarceration's effect on economic mobility. Washington, DC: The Pew Charitable Trusts. 
Wheelock, D., \& Uggen, C. (2006), Race, poverty, and punishment: The impact of criminal sanctions on racial, ethnic, and socioeconomic inequality. Ann Arbor, MI: National Poverty Center.

Wildeman, C., \& Wakefield, S. (2014). The long arm of the law: The concentration of incarceration in families in the era of mass incarceration. Journal of Gender, Race and Justice, 17(2), 367-389.

Yocum, A., \& Nath, S. (2011). Anticipating father reentry: A qualitative study of children's and mother's experiences. Journal of Offender Rehabilitation, 50(5), 286-304.

Zahn-Waxler, C., Klimes-Dougan, B., \& Slattery, M. J. (2000). Internalizing problems of childhood and adolescence: Prospects, pitfalls, and progress in understanding the development of anxiety and depression. Development and Psychopathology, 12(3), 433466. 